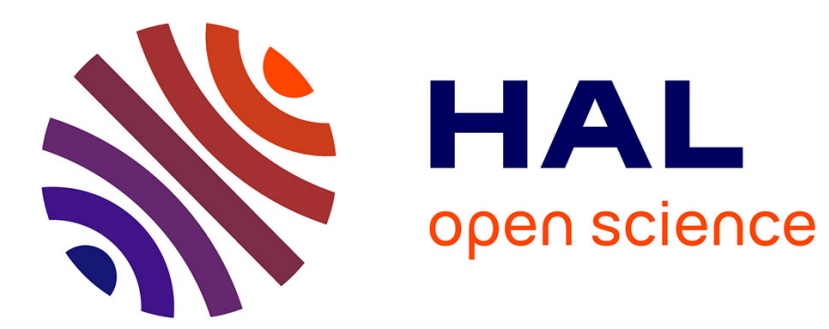

\title{
An On-line Method for Stator Fault Detection in Multi-phase PMSM Drives
}

\author{
Fabien Meinguet, Eric Semail, Johan Gyselinck
}

\section{To cite this version:}

Fabien Meinguet, Eric Semail, Johan Gyselinck. An On-line Method for Stator Fault Detection in Multi-phase PMSM Drives. Vehicle Power and Propulsion Conference, Sep 2010, France. pp.1-6, 10.1109/VPPC.2010.5728998 . hal-00794280

\section{HAL Id: hal-00794280 \\ https://hal.science/hal-00794280}

Submitted on 25 Feb 2013

HAL is a multi-disciplinary open access archive for the deposit and dissemination of scientific research documents, whether they are published or not. The documents may come from teaching and research institutions in France or abroad, or from public or private research centers.
L'archive ouverte pluridisciplinaire HAL, est destinée au dépôt et à la diffusion de documents scientifiques de niveau recherche, publiés ou non, émanant des établissements d'enseignement et de recherche français ou étrangers, des laboratoires publics ou privés. 


\title{
An On-line Method for Stator Fault Detection in Multi-phase PMSM Drives
}

\author{
Fabien Meinguet*, Eric Semail**, Johan Gyselinck* \\ *BEAMS, Université Libre de Bruxelles, Brussels, Belgium \\ **L2EP, Ecole Nationale Supérieure d'Arts et Métiers, Lille, France \\ e-mail: Fabien.Meinguet@ulb.ac.be
}

\begin{abstract}
This paper deals with an on-line fault detection method for multi-phase PMSM drives. The method is based on the detection of the stator current positive- and negative sequence fundamental components expressed in the stationary $\alpha \beta$ reference frame. These components allow calculating a fault index used for the detection of stator faults, such as open-circuit faults. The decision criterion is based on the CUSUM algorithm. A model of a five-phase machine with one single-phase opencircuit is derived and validated with experimental results. Then, it is shown that the proposed method achieves fault detection on a wide speed range and even during speed transient.
\end{abstract}

\section{INTRODUCTION}

Due to their attractive properties, multi-phase machines have been investigated for transport applications such as hybrid electric vehicle [1], [2] and ship propulsion [3]. The advantages of multi-phase machines over three-phase machines are among others a higher availability, higher power density and fault-tolerance.

A closed-loop control will generally be required to obtain good dynamic properties. Thus, the drive will be composed of a multi-phase machine, a multi-leg inverter and additional sensors, i.e. current sensors and possibly speed/position sensors. Condition monitoring of the drive should then take all of these components and their failures into account.

A review summarizing the different faults related to machines is given in [4], while inverter faults have been considered in [5]-[7]. Stator faults include: open-circuit faults and short-circuit in the windings (turn-to-turn, phase-to-phase or phase-to-neutral). Most of these faults are asymmetric, the "amount of asymmetry" being dependent of the type of fault and its respective severity (number of turns shorted, number of open-circuit...). As most of the closed-loop controllers are only derived for symmetrical machines, it is very important to study their reaction when a fault occurs and the impact on the fault detection method [8].

Assuming the drive can be maintained in operation after the fault has occurred, i.e. the drive is fault-tolerant to the considered fault, fault detection is still required to plan a repair operation. The fault detection could also be necessary for the controller if there is a control reconfiguration implemented [9]. For example, [10]-[12] deal with opencircuit faults by calculating new current references, but none of these works deal with the fault detection. Although it seems obvious to detect an open-circuit fault with current measurements, a direct measurement of the phase currents

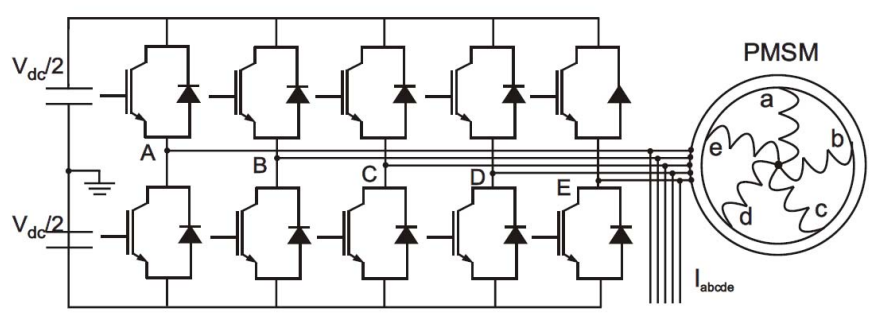

Fig. 1. Drive topology: a five-leg VSI supplying a five-phase PMSM.

can lead to a wrong diagnostic if we consider sensor faults as well.

Diagnostic methods have been considered in several survey papers [4], [13]-[15]. Motor current-based analysis seems one of the most suited for drive applications as the phase currents are measured anyway. However, frequency analysis is not well-suited for most vehicle applications as the operating point can change at any time, i.e. in urban driving.

In this paper, we describe an original method for detecting an abnormal asymmetrical behavior in five-phase PMSM drives and we apply it for an open-circuit fault. We focus on the current positive- and negative-sequence fundamental components instead of the spectrum. In section II, the drive model is derived. Next, section III describes a structure based on adaptive filters allowing to synchronize on the positive and negative fundamental components very quickly and with a good rejection of the disturbances [16], [17]. The decision criterion is based on the CUSUM algorithm [18]. Then, simulation results are presented in section IV. The influence of several parameters such as the presence of third harmonic in the electromotive force (emf) and in the phase currents and the controller bandwidth are discussed. Finally, experimental results showing the effectiveness of the method are presented in section $\mathrm{V}$.

\section{DRIVE MODEL}

In this section we describe the drive model composed of a five-phase star-connected PMSM and a five-leg voltage source inverter (VSI) as shown in Fig. 1. The neutral point is not connected and all the phase currents are measured. In what follows, we consider that effects of saliency and saturation are negligible. The stator equations expressed in the abcde reference frame are given by: 

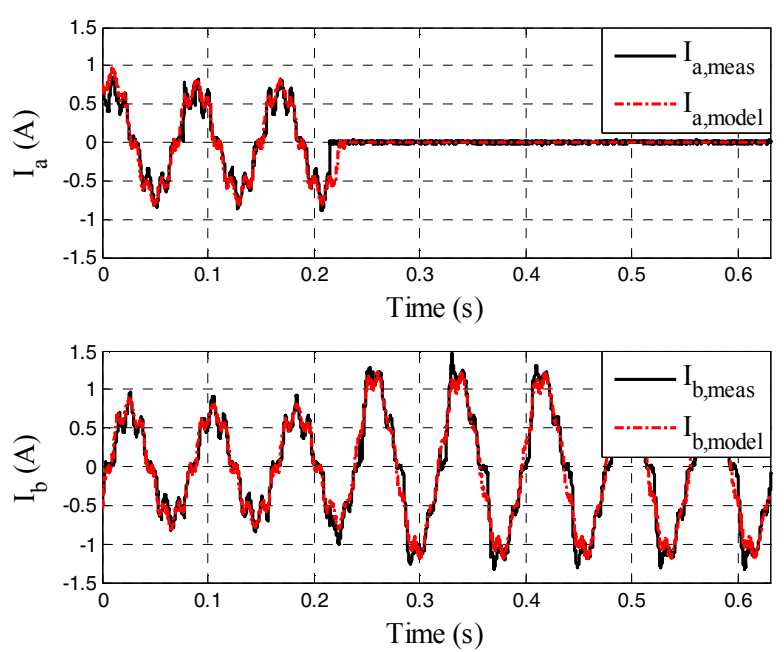

Fig. 2. Comparison of measured and simulated $a$ - and $b$-phase currents when a single-phase open-circuit fault occurs in the $a$-phase.

$$
\left[\begin{array}{l}
V_{a}-V_{n} \\
V_{b}-V_{n} \\
V_{c}-V_{n} \\
V_{d}-V_{n} \\
V_{e}-V_{n}
\end{array}\right]=R_{s}\left[\begin{array}{c}
I_{a} \\
I_{b} \\
I_{c} \\
I_{d} \\
I_{e}
\end{array}\right]+\left[\begin{array}{ccccc}
L & M_{1} & M_{2} & M_{2} & M_{1} \\
M_{1} & L & M_{1} & M_{2} & M_{2} \\
M_{2} & M_{1} & L & M_{1} & M_{2} \\
M_{2} & M_{2} & M_{1} & L & M_{1} \\
M_{1} & M_{2} & M_{2} & M_{1} & L
\end{array}\right] \frac{d}{d t}\left[\begin{array}{c}
I_{a} \\
I_{b} \\
I_{c} \\
I_{d} \\
I_{e}
\end{array}\right]+\left[\begin{array}{c}
E_{a} \\
E_{b} \\
E_{c} \\
E_{d} \\
E_{e}
\end{array}\right]
$$

where $R_{s}$ is the stator resistance, $L, M_{1}$ and $M_{2}$ are the stator phase self and mutual inductances, $V_{x}, I_{x}$ and $E_{x}$ are the $x$ phase voltage with respect to a virtual dc-link middle point, the $x$-phase current and the emf induced by the magnets in phase $x$ respectively $(x \in\{a, b, c, d, e\})$. As the neutral point is not connected, the sum of the phase currents is equal to zero:

$$
I_{a}+I_{b}+I_{c}+I_{d}+I_{e}=0 .
$$

From (1) and (2), the voltage $V_{n}$ between the neutral point of the machine and the inverter middle point is given by:

$$
V_{n}=\frac{1}{5} \sum_{i=a}^{e}\left(V_{i}-E_{i}\right)
$$

The model of the machine with one open phase is obtained by changing one of the state variables. If the fault occurs in the $x$-phase, this phase current becomes zero and thus no longer constitutes a state variable. Conversely, the floating voltage $V_{x}$ becomes a state variable, but as it gives no relevant information on the system, the line and the column relative to the $x$-phase can be removed from (1). In case the open-circuit fault occurs in phase $a, V_{n}$ becomes:

$$
\begin{aligned}
V_{n}=\frac{1}{4} \sum_{i=b}^{e}\left(V_{i}-E_{i}\right)-\frac{1}{4} M_{1} & \left(\frac{d I_{c}}{d t}+\frac{d I_{d}}{d t}\right) \\
& -\frac{1}{4} M_{2}\left(\frac{d I_{b}}{d t}+\frac{d I_{e}}{d t}\right) .
\end{aligned}
$$

In comparison with (3), it has to be noted that derivative terms have appeared. This is due to the fact that the machine has lost some of its symmetrical properties.

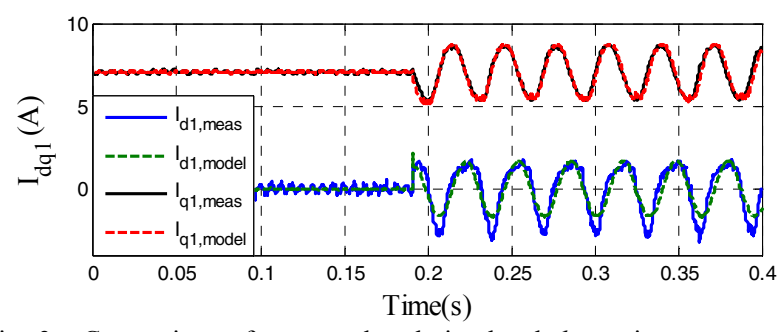

Fig. 3. Comparison of measured and simulated $d_{1} q_{1}$-axis currents when a single-phase open-circuit fault occurs in the $b$-phase.

Introducing (4) in the reduced system extracted from (1), we obtain:

$$
\begin{aligned}
& {\left[\begin{array}{l}
V_{b} \\
V_{c} \\
V_{d} \\
V_{e}
\end{array}\right]=R_{s}\left[\begin{array}{c}
I_{b} \\
I_{c} \\
I_{d} \\
I_{e}
\end{array}\right]+\left[\begin{array}{l}
E_{b} \\
E_{c} \\
E_{d} \\
E_{e}
\end{array}\right]+\left[\begin{array}{c}
\frac{1}{4} \sum_{i=b}^{e}\left(V_{i}-E_{i}\right) \\
\frac{1}{4} \sum_{i=b}^{e}\left(V_{i}-E_{i}\right) \\
\frac{1}{4} \sum_{i=b}^{e}\left(V_{i}-E_{i}\right) \\
\frac{1}{4} \sum_{i=b}^{e}\left(V_{i}-E_{i}\right)
\end{array}\right]+} \\
& {\left[\begin{array}{cccc}
L-\frac{1}{4} M_{2} & \frac{3}{4} M_{1} & M_{2}-\frac{1}{4} M_{1} & \frac{3}{4} M_{2} \\
M_{1}-\frac{1}{4} M_{2} & L-\frac{1}{4} M_{1} & \frac{3}{4} M_{1} & \frac{3}{4} M_{2} \\
\frac{3}{4} M_{2} & \frac{3}{4} M_{1} & L-\frac{1}{4} M_{1} & M_{1}-\frac{1}{4} M_{2} \\
\frac{3}{4} M_{2} & M_{2}-\frac{1}{4} M_{1} & \frac{3}{4} M_{1} & L-\frac{1}{4} M_{2}
\end{array}\right] \frac{d}{d t}\left[\begin{array}{c}
I_{b} \\
I_{c} \\
I_{d} \\
I_{e}
\end{array}\right] .}
\end{aligned}
$$

The Concordia/Clarke and Park transformations extended to multi-phase machines can be applied to (1) to obtain the model used for the fault detection and the closed-loop control respectively. These transformations are defined by the relations (6) and (7) with the transformation matrices expressed in (8) and (9).

$$
\left[X_{\alpha_{1} \beta_{1} \alpha_{3} \beta_{3} 0}\right]=\frac{2}{5}[C]\left[X_{a b c d e}\right]
$$

$$
\left[X_{d_{1} q_{1} d_{3} q_{3} 0}\right]=[R]\left[X_{\alpha_{1} \beta_{1} \alpha_{3} \beta_{3} 0}\right]
$$

$$
[C]=\left[\begin{array}{ccccc}
1 & \cos \frac{2 \pi}{5} & \cos \frac{4 \pi}{5} & \cos \frac{6 \pi}{5} & \cos \frac{8 \pi}{5} \\
0 & \sin \frac{2 \pi}{5} & \sin \frac{4 \pi}{5} & \sin \frac{6 \pi}{5} & \sin \frac{8 \pi}{5} \\
1 & \cos \frac{4 \pi}{5} & \cos \frac{8 \pi}{5} & \cos \frac{2 \pi}{5} & \cos \frac{6 \pi}{5} \\
0 & \sin \frac{4 \pi}{5} & \sin \frac{8 \pi}{5} & \sin \frac{2 \pi}{5} & \sin \frac{6 \pi}{5} \\
\frac{1}{\sqrt{2}} & \frac{1}{\sqrt{2}} & \frac{1}{\sqrt{2}} & \frac{1}{\sqrt{2}} & \frac{1}{\sqrt{2}}
\end{array}\right]
$$

$$
[R]=\left[\begin{array}{ccccc}
\cos \theta_{e} & \sin \theta_{e} & 0 & 0 & 0 \\
-\sin \theta_{e} & \cos \theta_{e} & 0 & 0 & 0 \\
0 & 0 & -\cos 3 \theta_{e} & \sin 3 \theta_{e} & 0 \\
0 & 0 & \sin 3 \theta_{e} & \cos 3 \theta_{e} & 0 \\
0 & 0 & 0 & 0 & 1
\end{array}\right]
$$

where $\theta_{e}$ is the electrical position of the rotor. When the machine has no fault, (6) allows to split the harmonic content of the considered variable (i.e. current, emf or voltage) into several families of harmonics, the fundamental and the ninth harmonic components being linked to the two first lines, denoted by subscript ' 1 ', and the third and the seventh harmonic, components being linked to the third and fourth lines with the subscript ' 3 ' [3]. 


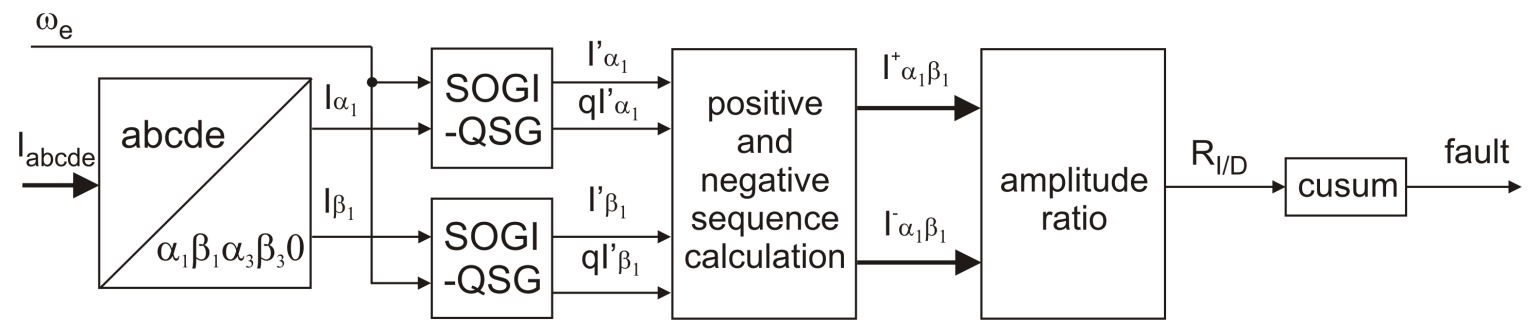

Fig. 4. Fault detection scheme for asymmetrical faults.

The last line is linked to the fifth-harmonic component, which is not relevant as the neutral is not connected. The Park transformation (7) allows obtaining these variables in the rotating reference frames of their main harmonic component. Simple PI controllers are used for the current control.

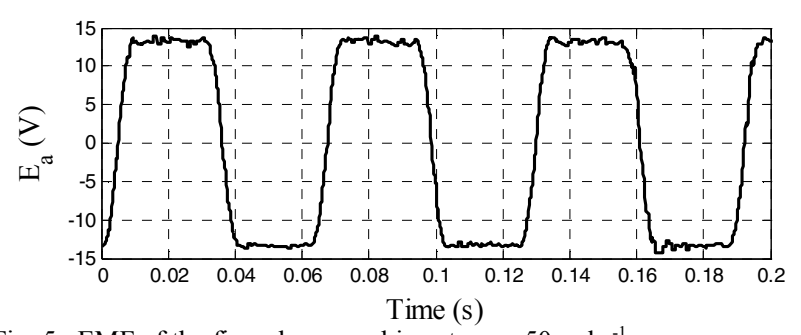

Fig. 5. EMF of the five-phase machine at $\omega_{m}=50 \mathrm{rad} \mathrm{s}^{-1}$.

Figs. 2 and 3 show the comparison between measurements and simulation results. Parameters of the machine are [19]: $R_{s}=2.24 \Omega, L=18 \mathrm{mH}, M_{1}=0.25 \mathrm{mH}, M_{2}=-0.75 \mathrm{mH}$, the emf, shown in Fig. 5, has a fundamental emf constant $k_{e}=$ $0.32 \mathrm{Vs} \mathrm{rad}^{-1}$ (mechanical radian), the ratios of higher-order harmonics related to fundamental are: $k_{3}=28.5 \%, k_{5}=$ $12.4 \%, k_{7}=5.1 \%$ and $k_{9}=1.7 \%$. $V_{d c}=100 \mathrm{~V}$ for the test of Fig. 2 and $150 \mathrm{~V}$ for the test of Fig. 3. PI current controller proportional gains are $G_{p, 1}=5$ and $G_{p, 3}=3$ and integral gains are $G_{i, 1}=1200$ and $G_{i, 3}=300$ for the fundamental and thirdharmonic components respectively. Fig. 2 shows the $a$ - and $b$ phase currents when a fault occurs in the $a$-phase at the time $t=0.22 \mathrm{~s}\left(\omega_{\mathrm{m}}=40 \mathrm{rad} \mathrm{s}^{-1}\right)$, while Fig. 3 shows the $d_{1} q_{1}$-axis currents when a fault occurs in the $b$-phase at the time $\mathrm{t}=$ $0.19 \mathrm{~s}\left(\omega_{\mathrm{m}}=50 \mathrm{rad} \mathrm{s}^{-1}\right)$. An analysis of the curves and data shows that there is a good agreement between the simulations and the measurements, except for the seventh current harmonic that was higher in the measurements and for $I_{d l}$ that has deeper measured notches in case of fault.

\section{FAULT DETECTION AND ISOLATION SCHEME}

Fig. 4 depicts the fault detection scheme described in this section. As inputs we have the measured abcde currents, which are transformed following (6). For the sake of fault detection, we only use the current fundamental components $I_{\alpha 1 \beta 1}$ because we assume that the fundamental currents are the major contributors to torque before and after the fault has occurred. These $\alpha_{1} \beta_{1}$ components are filtered and quadrature signals $\left(q I_{\alpha l}\right.$ and $\left.q I_{\beta l}\right)$ are generated in the second-order generalized integrator-based quadrature signal generator (SOGI-QSG) detailed below.
The output signals of the SOGI-QSG allow calculating the $\alpha_{1} \beta_{1}$ positive- and negative-sequence components [17]:

$$
\begin{aligned}
& {\left[I_{\alpha_{1} \beta_{1}}^{+}\right]=\frac{1}{2}\left[\begin{array}{cc}
1 & -q \\
q & 1
\end{array}\right]\left[I_{\alpha_{1} \beta_{1}}\right]} \\
& {\left[I_{\alpha_{1} \beta_{1}}^{-}\right]=\frac{1}{2}\left[\begin{array}{cc}
1 & q \\
-q & 1
\end{array}\right]\left[I_{\alpha_{1} \beta_{1}}\right]}
\end{aligned}
$$

where $q=e^{-\mathrm{j} \pi / 2}$ is a phase-shift time-domain operator that makes an original signal $90^{\circ}$-lagging.

Then, we calculate the amplitudes of the current negativeand positive sequence components, from which the fault index $\mathrm{R}_{\mathrm{I} / \mathrm{D}}$ is derived:

$$
R_{I / D}=\frac{\left|I_{\alpha_{1} \beta_{1}}^{-}\right|}{\left|I_{\alpha_{1} \beta_{1}}^{+}\right|}=\frac{\sqrt{I_{\alpha_{1}}^{-}{ }^{2}+I_{\beta_{1}}^{-2}}}{\sqrt{I_{\alpha_{1}}^{+}{ }^{2}+I_{\beta_{1}}^{+}{ }^{2}}}
$$

This fault index gives the extent of unbalance of the drive. $\mathrm{R}_{\mathrm{I} / \mathrm{D}}$ is then the input of the CUSUM algorithm taking the decision to set a fault flag or not.

\section{A. Second-order generalized integrator for quadrature signals generation}

The measured abcde currents can contain a lot of noise and harmonic components. However, we only consider the fundamental component for the fault detection. To obtain good filtering properties with no lag for frequency-variable signals, the authors of [17] have proposed to use an adaptive filtering. So, $I_{\alpha 1}$ and $I_{\beta 1}$ are taken as inputs $X(s)$ of a bandpass filter with a transfer function $D(s)$ such that:

$$
D(s)=\frac{X^{\prime}(s)}{X(s)}=\frac{k \omega_{f} s}{s^{2}+k \omega_{f} s+\omega_{f}^{2}}
$$

where $X^{\prime}(s)$ is the filter output, $k$ a damping factor, $s$ the Laplace variable and $\omega_{f}$ the resonant frequency of the filter. For synchronous machines, $\omega_{f}$ is equal to the synchronous frequency $\omega_{e}$, which is then an input of the adaptive filters. The phase-shift time-domain operator $q$ already mentioned can also be implemented with an adaptive filter. Its transfer function $Q(s)$ is:

$$
Q(s)=\frac{q X^{\prime}(s)}{X(s)}=\frac{k \omega_{f}^{2}}{s^{2}+k \omega_{f} s+\omega_{f}^{2}} .
$$

It is obvious that a steady-state condition where the fundamental frequency of the $\alpha_{1} \beta_{I}$-axis currents is equal to $\omega_{f}$, i.e. $s=j \omega_{f}$, will give $D\left(j \omega_{f}\right)=1$ and $Q\left(j \omega_{f}\right)=-j=q$. The higher harmonic components will be attenuated. 


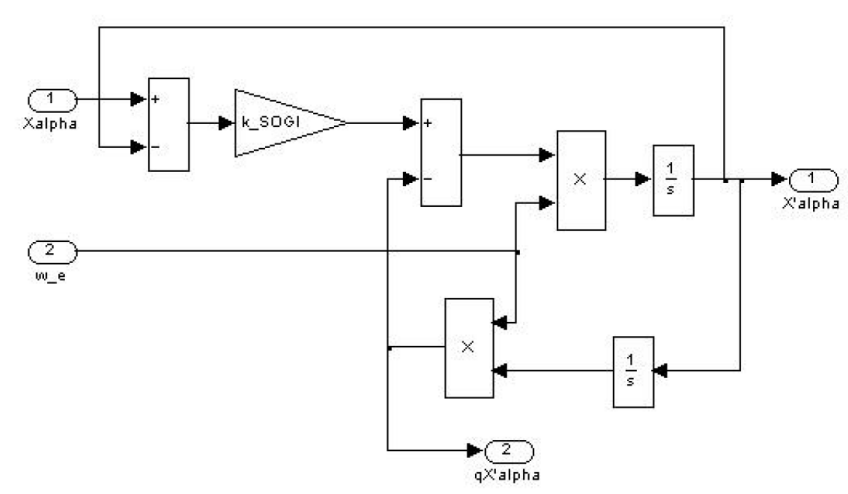

Fig. 6. Implementation of the SOGI-QSG.

A graphic representation of the SOGI-QSG implementation is given in Fig. 6.

\section{B. CUSUM algorithm}

A theoretical background concerning the CUSUM algorithm ('CUMulative SUM') can be found in [18]. Basically, this algorithm acts like an integrator that allows detecting variations in signal properties, such as the mean value. It is thus an ideal candidate to detect a fault causing an unbalance if we apply the algorithm to the variable $R_{I / D}$.

In its simplified version, the algorithm consists in computing a function $g$ at each sample time $k$ :

$$
g(k)=\max \left(0, g(k-1)+\left(\left(R_{I / D}(k)-\frac{\mu_{0}+\mu_{1}}{2}\right)\right)\right.
$$

where $\mu_{0}$ and $\mu_{1}$ are the mean value of the signal before and after the fault. It can be interpreted as follows: before the fault the average value of $R_{I / D}-\left(\mu_{0}+\mu_{1}\right) / 2=\left(\mu_{0}-\mu_{1}\right) / 2$ will be negative as $\mu_{1}$ is greater than $\mu_{0}$ and $g$ will be maintained to zero. After the fault the term becomes positive and $g$ begins to increase with a slope equal to $\Delta g / \Delta k=\left(\mu_{1}-\mu_{0}\right) / 2$. When $g$ will reach a user-chosen threshold $h$, the system will set up an error flag. As the rising slope is known, the threshold $h$ can be chosen so that the flag is activated in a given time $\Delta t_{\text {detection }}$ :

$$
\Delta t_{\text {detection }}=h \frac{\Delta k}{\Delta g} t_{s} .
$$

where $t_{s}$ is the sampling time. Obviously, (16) relies on the fact that $\mu_{I}$ is known, or at least roughly known. An example based on simulation results is shown in the Fig. 7 where $\mu_{0}=$ $0, \mu_{1}=0.15, \Delta t_{\text {detection }}=0.4 \mathrm{~s}$ and $t_{s}=1 \mathrm{~ms}$, which gives $h=30$. It takes a bit more than $0.4 \mathrm{~s}$ to set up the fault flag, the error coming from the value of $R_{I / D}$ a bit lower than 0.15 and from the time needed for the fault index to cross $\left(\mu_{1}-\mu_{0}\right) / 2$.

\section{SIMULATION RESULTS}

\section{A. Influence of the drive parameters}

Several parameters have an influence on the behavior of the drive after the fault has occurred. Among others we have: machine speed, load, controller bandwidths and ratio of third harmonic in the emf and in the current. In this subsection we study the influence of these parameters on the fault detection
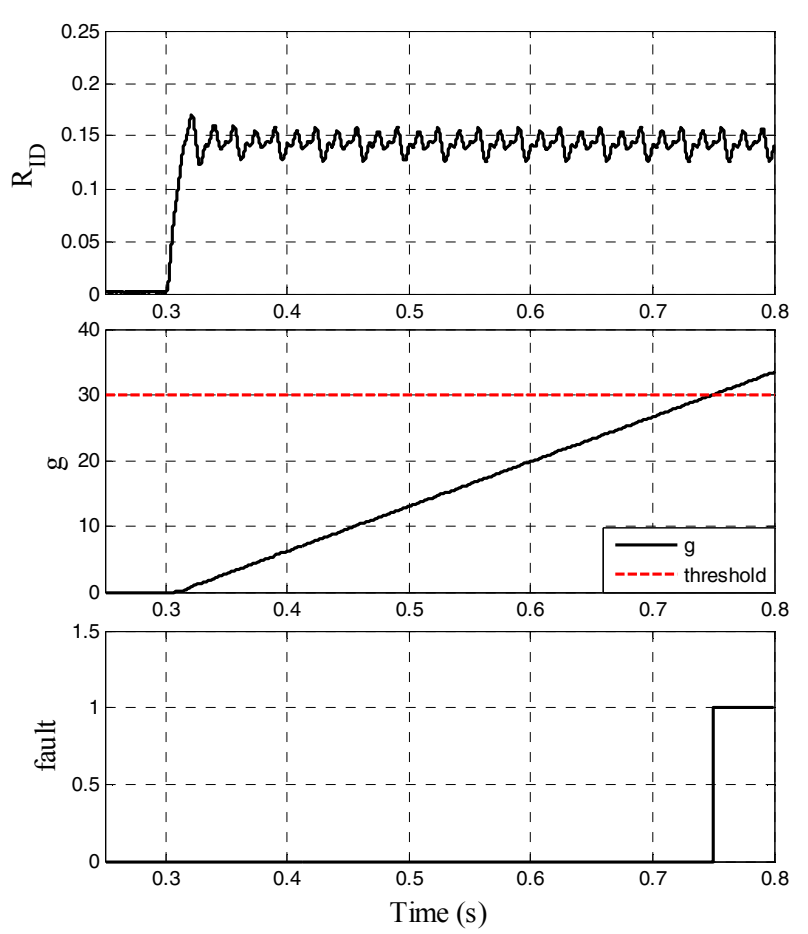

Fig. 7. Simulation results of the fault detection scheme in case of one open phase fault. From top to bottom: fault index $R_{I / D}$, CUSUM function $g$ and fault flag.

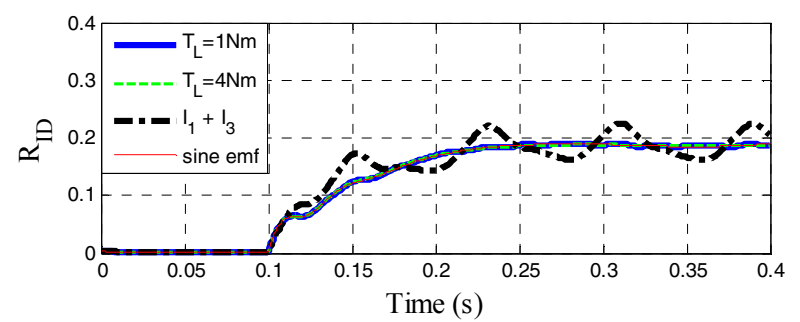

Fig. 8. Comparison of the temporal evolution of $R_{I / D}$ in case of fault for four different cases: $T_{L}=1 \mathrm{Nm}, T_{L}=4 \mathrm{Nm}, T_{L}=1 \mathrm{Nm}$ with third harmonic current and $T_{L}=1 \mathrm{Nm}$ without harmonic components in the emf.

method, i.e. the influence of these variables on $\mu_{1}$ (the mean value of $\left.R_{I / D}\right)$. The objective is to determine $\mu_{1}$ so that the fault can be detected on a wide speed range and in a given time $\Delta t_{\max }$. Fig. 8 shows the fault index $R_{I / D}$ in function of the time when a fault occurs at time $t=0.1 \mathrm{~s}$. The machine speed is constant and equal to $20 \mathrm{rad} \mathrm{s}^{-1}$. Controller gains are the same as in section II. $k_{S O G I}=\sqrt{ } 2$. Four different simulation results have been plotted in this figure: the first has a load torque $T_{L}=1 \mathrm{Nm}$ with fundamental currents only; the second has $T_{L}=4 \mathrm{Nm}$ with fundamental currents only; the third has $T_{L}=1 \mathrm{Nm}$ with a ratio of currents $I_{q 3} / I_{q 1}=0.28$; the fourth has $T_{L}=1 \mathrm{Nm}$ and only a fundamental harmonic component in the emf (higher-order harmonic components have been set to zero). It can be seen that the first, the second and the fourth curves are almost superposed, meaning that the amplitude of the load torque and the amplitude of the emf harmonic components have no influence on the fault index. 


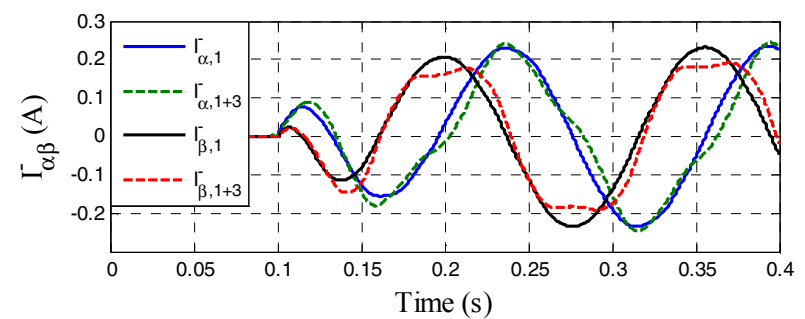

Fig. 9. Comparison of the temporal evolution of the negative sequence of $I_{\alpha \beta}$ in case of fault for four different cases: $T_{L}=1 \mathrm{Nm}, T_{L}=4 \mathrm{Nm}, T_{L}=1 \mathrm{Nm}$ with third harmonic current and $T_{L}=1 \mathrm{Nm}$ without harmonic components in the emf.

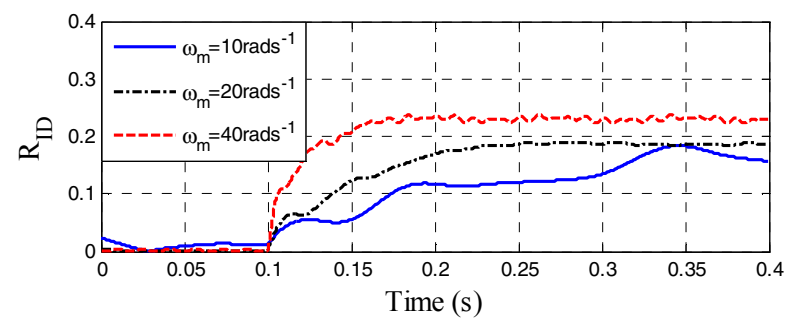

Fig. 10. Comparison of the temporal evolution of $R_{I / D}$ in case of fault for different speeds: $\omega_{\mathrm{m}}=10 \mathrm{rad} \mathrm{s}^{-1}, \omega_{\mathrm{m}}=20 \mathrm{rad} \mathrm{s}^{-1}$ and $\omega_{\mathrm{m}}=40 \mathrm{rad} \mathrm{s}^{-1}$.

However, we can observe a ripple in case there is a thirdharmonic current component. This can be understood from Fig. 9 where we can see the related negative sequence current components of $I_{\alpha \beta}$. In case of fault, the Concordia transformation do not split the harmonic components into families anymore as described in section II. A FFT analysis of $I_{\alpha 1 \beta 1}$ reveals the presence of third and fifth harmonic components, which are reflected in the negative sequence of $I_{\alpha 1 \beta 1}$ despite the adaptive filtering. Thus, the current thirdharmonic component increases the ripple on the fault index. Nevertheless, this has almost no consequence on the fault detection as the CUSUM algorithm acts like an integrator. So, only the mean value of $R_{I / D}$ matters, which is the same as the mean of the three other simulations.

Fig. 10 shows the influence of the speed on the fault index when a fault occurs. The value of the fault index increases with increasing speed. Moreover, we can observe that the time required obtaining the steady state value of $R_{I / D}$ decreases with the speed. This is due to the lag caused by the adaptive filtering.

Fig. 11 shows the influence of the controller gains on the fault index. The chosen gains are those of section II $\left(G_{i n i t}\right)$, those gains divided by 5 and multiplied by $5\left(G_{\text {init }} / 5\right.$ and $G_{\text {init }}$ $\mathrm{x} 5$ respectively). It can be seen that the fault index decreases with increasing gain values. This is due to the PI controller response that is faster when the gains are higher, reducing the unbalance of the drive.

\section{B. Speed transient}

One of the main advantages of the proposed method compared to frequency-based method is that it is possible to detect the fault even while the speed is changing.

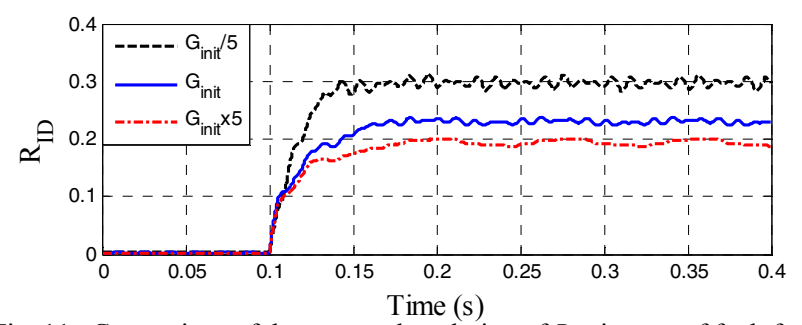

Fig. 11. Comparison of the temporal evolution of $R_{I / D}$ in case of fault for different gains: $G_{\text {init }} / 5, G_{\text {init }}$ and $G_{\text {init }} \times 5\left(\omega_{\mathrm{m}}=40 \mathrm{rad} \mathrm{s}^{-1}\right)$.

This is shown in Fig. 12 where a fault occurs at the time $t=$ 0 s while the speed increases. We can again observe that the value of the fault index increases with the speed.
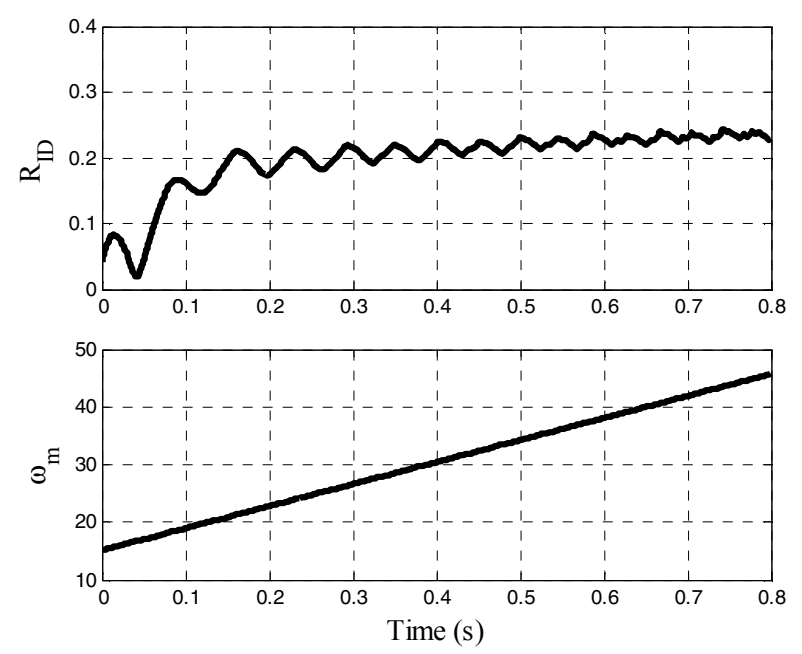

Fig. 12. Fault detection in case of fault while the speed changes.

\section{EXPERIMENTAL RESULTS}

Experimental results have been obtained with the test bench shown on Fig. 13. The bench is composed of a fivephase machine, a magnetic powder brake and a flywheel. Control and data acquisition have been performed with a dSPACE 1005 system. From simulation results, a value of $\mu_{1}$ $=0.15$ has been adopted. This corresponds to the minimum value of $R_{I / D}$ that has been observed. It means also that any asymmetrical fault leading to an asymmetry higher than $7.5 \%$ will be detected. The detection threshold has been set to $h=$ 200 and $t_{s}=0.1 \mathrm{~ms}$. Following (16), the detection time should be $\Delta t_{\text {detection }}=0.2667 \mathrm{~s}$.

Fig. 14 shows experimental results when a fault occurs at the time $t=0.33 \mathrm{~s}$. The controller gains used are the set $G_{\text {init }}$ and the mechanical speed is equal to $50 \mathrm{rad} \mathrm{s}^{-1}$. We can see that there is a good agreement between the measurements and the predicted values. As seen from the CUSUM functions, we can conclude that the ripple on $R_{I / D}$ has no impact on the fault detection method. However, the detection time is lower than expected. This is due to the fact that $R_{I / D}$ is greater than the selected $\mu_{I}=0.15$. 


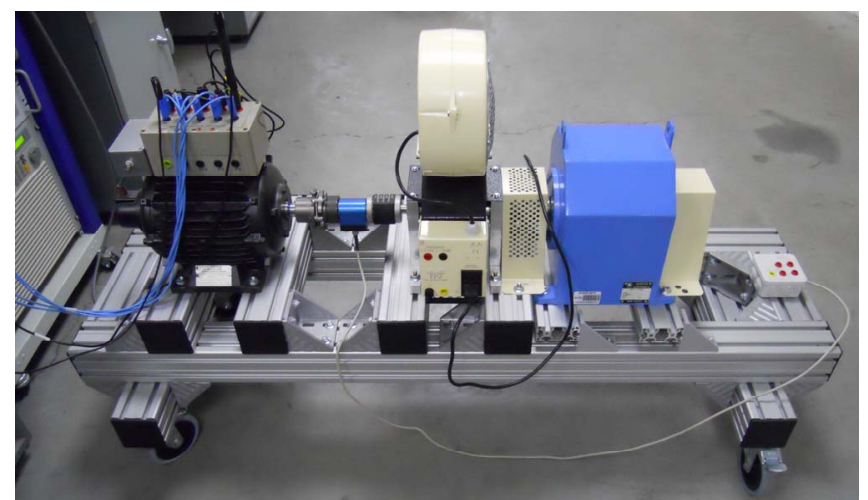

Fig. 13. Test bench composed of (from the left to the right): a five-phase PMSM, a magnetic powder brake and a flywheel.

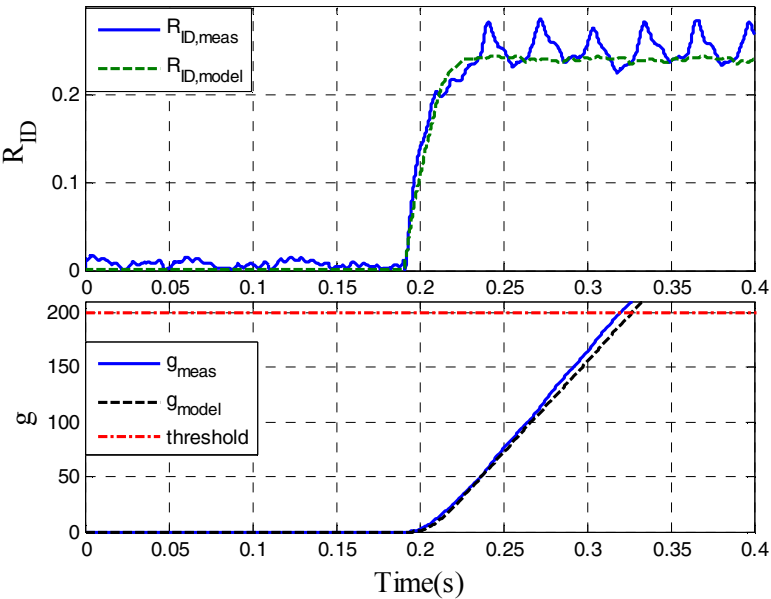

Fig. 14. Comparison of RID for the experimental results and the model in case of fault $\left(\omega_{\mathrm{m}}=50 \mathrm{rad} \mathrm{s}^{-1}, T_{L}=5.81 \mathrm{Nm}\right)$.

The fault detection method could be improved to make the recognition of the fault by adapting $\mu_{1}$ in function of the controller gains and the speed. In such a way the slope of the CUSUM function should become a characteristic of the fault.

\section{CONCLUSION}

In this paper we presented a model a of five-phase PMSM with one single-phase open-circuit fault. The model showed a good agreement with the experimental results. Then, we propose a fault detection scheme based on the detection of the fundamental negative-sequence component of the currents expressed in the stator reference frame. The method allows detecting the fault even while the speed changes. We studied the influence of the drive operating point on the fault detection scheme and showed that the controller gains and the mechanical speed had an influence on the value of the fault index. Finally, experimental results validated the whole fault detection method; even if a better fault recognition should be investigated.

\section{ACKNOWLEDGMENT}

Fabien Meinguet would like to thank the Belgian Fund for training in Research in Industry and in Agriculture (F.R.I.A.) for the funding of this research project.

\section{REFERENCES}

[1] L. Parsa and H. Toliyat, "Fault-tolerant interior-permanent-magnet machines for hybrid electric vehicle applications", IEEE Trans. on Vehicular Technology, Vol. 56, No. 4, pp: 1546-1552, July 2007.

[2] A. Bruyere, E. Semail, A. Bouscayrol, F. Locment, J.M. Dubus and J.C. Mipo, "Modeling and Control of a seven-phase Claw-Pole Integrated Starter Alternator for Micro-hybrid Automotive Applications", IEEE Vehicle Power and Propulsion Conference (VPPC), September 2008.

[3] F. Scuiller, J.-F. Charpentier, E. Semail and S. Clenet, "Comparison of two 5-phase permanent magnet machine winding configurations. Application on naval propulsion specifications ", Proc. of the International Electric Machines and Drives Conference (IEMDC), Vol. 1, pp: 34-39, May 2007.

[4] S. Nandi, H.A. Toliyat and X. Li, "Condition monitoring and fault diagnosis of electrical motors - a review", IEEE Trans. on Energy Conversion, Vol. 20, No. 4, pp: 719-729, December 2005.

[5] B. Welchko, T. Lipo, T. Jahns, S. Schulz, "Fault tolerant three-phase AC motor drive topologies: a comparison of features, cost and limitations", IEEE Trans. on Power Electronics, Vol. 19, No. 4, pp: 539-546, July 2004.

[6] B.C. Mecrow, D.J. Atkinson, A.G. Jack, S. Green, J.A. Haylock and J. Coles, "The need for fault tolerance in an aeroengine electric fuel control system", IEE Colloquium on Electrical Machines and Systems for the More Electric Aircraft, Ref. No. 1999/180, pp: 9/1-9/5, 1999.

[7] S. Bolognani, M. Zordan and M. Zigliotto, "Experimental fault-tolerant control of a PMSM drive", IEEE Trans. on Industrial Electronics, Vol. 47, No. 5, pp: 1134-1141, October 2000.

[8] A. Bellini, F. Filippetti, G. Franceschini and Carla Tassoni, "Closedloop control impact on the diagnosis of induction motors faults", IEEE Trans. On Industry Applications, Vol. 36, No. 5, pp: 1318- 1329, September/October 2000.

[9] F. Meinguet, J. Gyselinck, "Control strategies and reconfiguration of four-leg inverter PMSM drives in case of single-phase open-circuit faults", Proc. of the IEEE International Electric Machines and Drives Conference (IEMDC), paper ID 11117, May 2009.

[10] N. Bianchi, S. Bolognani, and M. Dai Pré, "Strategies for the faulttolerant current control of a five-phase permanent-magnet motor", IEEE Trans. on Industry Applications, Vol. 43, No. 4, pp: 960-970, July/August 2007.

[11] S. Dwari and L. Parsa, "Open-circuit fault tolerant control of five-phase permanent magnet motors with third-harmonic back-EMF", IEEE Industrial Electronics Conference (IECON), pp. 3114-3119, Nov. 2008.

[12] X. Kestelyn, E. Semail and Y. Crévits, "Generation of on-line optimal current references for multi-phase permanent magnet machines with open-circuited phases", Proc. of the IEEE International Electric Machines and Drives Conference (IEMDC), paper ID 10850, May 2009.

[13] M. El Hachemi Benbouzid, "A review of induction motors signature analysis as a medium for faults detection", IEEE Trans. on Industrial Electronics, Vol. 47, No.5, pp: 984-993, October 2000.

[14] A. Bellini, F. Filippetti, C. Tassoni, and G.-A. Capolino, "Advances in diagnostic techniques for induction machines", IEEE Trans. on Industrial Electronics, Vol. 55, No. 12, pp: 4109- 4126, December 2008.

[15] R. Tallam, Sang Bin Lee, G. Stone, G. Kliman, J. Yoo, T. Habetler and R. Harley, "A survey of methods for detection of stator-related faults in induction machines", IEEE Trans. On Industry Applications, Vol. 43, No. 4, pp: 920-933, July/August 2007.

[16] Fabien Meinguet and Johan Gyselinck, "Sensor and open-phase fault detection and isolation for three-phase AC drives, Proc. of the Power Electronics, Machines and Drives conference (PEMD), April 2010.

[17] P. Rodriguez, R. Teodorescu, I. Candela, A.V. Timbus, M. Liserre, F. Blaabjerg, "New positive-sequence voltage detector for grid synchronization of power converters under faulty grid conditions", Power Electronics Specialists Conference (PESC), June 2006.

[18] M. Blanke, M. Kinnaert, J. Lunze and M. Staroswiecki, "Diagnosis and fault-tolerant control”, Springer, Second Edition, Chapter 6, pp: 238263, 2006.

[19] X. Kestelyn, "Modélisation vectorielle multimachines pour la commande des ensembles convertisseurs-machines polyphasés ", $P h D$ Dissertation, Université de Lille 1, December 2003. 